\title{
Feasibility of self-sampled dried blood spot and saliva samples sent by mail in a population-based study
}

Amrit Kaur Sakhi ${ }^{1,2+}{ }^{2}$, Nasser Ezzatkhah Bastani ${ }^{2 \dagger}$, Merete Ellingjord-Dale ${ }^{2}$, Thomas Erik Gundersen ${ }^{3}$, Rune Blomhoff ${ }^{2,4}$ and Giske Ursin ${ }^{2,5,6^{*}}$

\begin{abstract}
Background: In large epidemiological studies it is often challenging to obtain biological samples. Self-sampling by study participants using dried blood spots (DBS) technique has been suggested to overcome this challenge. DBS is a type of biosampling where blood samples are obtained by a finger-prick lancet, blotted and dried on filter paper. However, the feasibility and efficacy of collecting DBS samples from study participants in large-scale epidemiological studies is not known. The aim of the present study was to test the feasibility and response rate of collecting self-sampled DBS and saliva samples in a population-based study of women above 50 years of age.

Methods: We determined response proportions, number of phone calls to the study center with questions about sampling, and quality of the DBS. We recruited women through a study conducted within the Norwegian Breast Cancer Screening Program. Invitations, instructions and materials were sent to 4,597 women. The data collection took place over a 3 month period in the spring of 2009.

Results: Response proportions for the collection of DBS and saliva samples were $71.0 \%(3,263)$ and $70.9 \%(3,258)$, respectively. We received 312 phone calls (7\% of the 4,597 women) with questions regarding sampling. Of the 3,263 individuals that returned DBS cards, 3,038 (93.1\%) had been packaged and shipped according to instructions. A total of 3,032 DBS samples were sufficient for at least one biomarker analysis (i.e. $92.9 \%$ of DBS samples received by the laboratory). 2,418 (74.1\%) of the DBS cards received by the laboratory were filled with blood according to the instructions (i.e. 10 completely filled spots with up to 7 punches per spot for up to 70 separate analyses). To assess the quality of the samples, we selected and measured two biomarkers (carotenoids and vitamin D). The biomarker levels were consistent with previous reports.
\end{abstract}

Conclusion: Collecting self-sampled DBS and saliva samples through the postal services provides a low cost, effective and feasible alternative in epidemiological studies.

Keywords: Dried blood spots, Saliva, Postal service, Carotenoids, Vitamin D

\section{Background}

A common challenge for large epidemiological studies is obtaining and transporting biological samples. This challenge is especially true for blood samples. Trained personnel are required to take blood samples, and thus participants either need to visit doctor's offices or

\footnotetext{
* Correspondence: giske.ursin@kreftregisteret.no

${ }^{\dagger}$ Equal contributors

${ }^{2}$ Department of Nutrition, Institute of Basic Medical Sciences, University of Oslo, 0316 Oslo, Norway

${ }^{5}$ Cancer Registry of Norway, P.O. Box 5313, 0304 Oslo, Norway

Full list of author information is available at the end of the article
}

specialized blood drawing centers, or study personnel need to visit the participants. Furthermore, blood samples typically must be shipped directly from the medical center to the receiving laboratory overnight in order to ensure the stability of the biomarkers. To overcome some of these challenges it has been suggested that participants could self-sample dried blood spots (DBS) for blood analysis and saliva samples for DNA analysis, and ship such specimens by postal service directly to the laboratory.

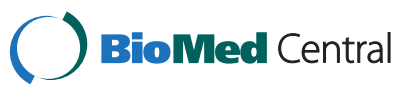

(c) 2015 Sakhi et al.; licensee BioMed Central. This is an Open Access article distributed under the terms of the Creative Commons Attribution License (http://creativecommons.org/licenses/by/4.0), which permits unrestricted use, distribution, and reproduction in any medium, provided the original work is properly credited. The Creative Commons Public Domain Dedication waiver (http://creativecommons.org/publicdomain/zero/1.0/) applies to the data made available in this article, unless otherwise stated. 
DBS is a form of biosampling where blood samples obtained by a finger-prick lancet are blotted on filter paper [1]. The DBS sample should be dried before being sent by regular mail, and transferred to $-80^{\circ} \mathrm{C}$ for long term storage at the receiving laboratory. Most biomarkers are stable in DBSs for months or years at ambient or refrigerator temperatures, and for even longer periods at $-80^{\circ} \mathrm{C}$. The DBS platform is especially advantageous in studies of infants and small children since it is minimally invasive and small volumes often are available $[2,3]$.

The feasibility of collecting such DBS samples from study participants in large-scale epidemiological studies is not known. Although the DBS analysis platform is routinely used for DNA, protein, virus, drugs and blood sampling in clinical practice [4-7], only a few studies have reported on the feasibility of postal collection of DBSs in population-based studies [8-10]. The expected response proportion is not known in large epidemiological studies. Specifically, it is not clear whether participants would be reluctant to take their own blood samples. It is also not known whether participants would be able to understand written instructions for obtaining and shipment of the blood sample adequately, and to what extent participants would contact study personnel with questions about the DBS protocol.

The aim of this study was to measure the feasibility of collecting self-collected DBS and saliva samples in a population-based study, where participants would be asked to ship the samples by standard postal service. Feasibility was measured by response proportion, the number of phone calls, number of adequate blood spots submitted and the quality of the blood samples.

To determine the quality of mailed DBS samples, we analyzed two key biomarkers, carotenoids and vitamin D (25-hydroxy-D3), in a subset of samples. Blood carotenoids may serve as biomarkers for fruit and vegetable intake [11-13]. They are lipid-soluble plant pigments with antioxidant activities [14]. Lutein, zeaxanthin, $\beta$ kryptoxanthin, $\alpha$-carotene, $\beta$-carotene, and lycopene are among the most studied carotenoids due to their abundance in food and plasma. Vitamin D is a fat-soluble secosteroid. Sun exposure plays a central role in vitamin D metabolism, as it is formed in the skin under the influence of UV light [15-17]. Both carotenoids and vitamin D are important biomarkers in epidemiological studies of nutrients and disease.

\section{Methods}

\section{Subjects and Study Design}

The present study was part of a larger project on diet and breast cancer in Norway [18]. The main aims of the large project were to gain insight into the effects of women's diet, genetics and hormones on the breast tissue, as monitored through mammographic density.
In 2006 and 2007, the Norwegian Breast Cancer Screening Program included a question in their standard questionnaire sent with the invitation letter for the mammographic screening appointment on whether the woman was willing to complete a dietary questionnaire, and receive blood and saliva sampling kits. A food frequency questionnaire (FFQ) was mailed to a random sample of 10,000 women who agreed. Out of them, 6,974 returned the dietary questionnaire. Blood and saliva sample collection kits were mailed to a random sample of 4,597 of those women who had returned the questionnaire, in the spring of 2009. This study was conducted over a period of about 3 months. The inclusion and characteristics of the study participants are shown in Figure 1 and Table 1.

The blood sampling kit consisted of two blood DBS cards (Protein Saver ${ }^{\mathrm{TM}} 903^{\mathrm{R}}$ Cards, Whatman, Sanford, USA), two lancets, one 5-mg desiccant pouch (Reàl Marine A/S Stavanger, Norway), one aluminum zip-lock bag (Whatman, Sanford, USA), Cutisoft ${ }^{\circ}$ wipes, Mesoft swabs (Mölnlycke Healthcare) and one small bandage. The airtight aluminum bag was used to protect the blood sample during shipment. The desiccant bag was included to remove any moisture from the DBS cards. To suppress the degradation of carotenoids in the DBS samples [1], the first two circles in the DBS cards were impregnated with a proprietary stabilizing solution supplied by Vitas AS, Oslo, Norway. The saliva sampling kit consisted of a saliva collection tube and a bag, Oragene ${ }^{\mathrm{Tm}}$ DNA Self-Collection Kit (DNA Genotek Inc., Kanata, ON, Canada). The bag protected the saliva sample during mailing. Detailed instructions for blood and saliva sample collection were mailed together with the sample collection kits (Additional file 1).

\section{Blood Samples \\ Validity of blood samples}

Upon receipt, the DBS cards were assessed by a trained research assistant for both validity and amount of blood

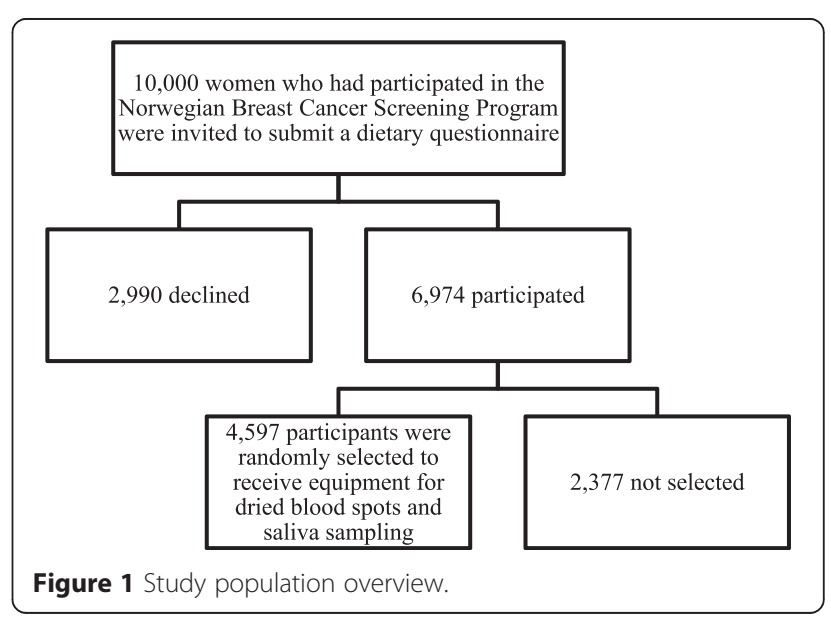


Table 1 Characteristics of the study participants

\begin{tabular}{|c|c|c|c|c|c|c|c|c|}
\hline \multirow{3}{*}{$\begin{array}{l}\text { Overall }(\mathrm{N}=4597) \\
\text { Variables }\end{array}$} & \multirow[b]{3}{*}{$\mathrm{N}$} & \multirow[b]{3}{*}{ Mean (SD) ${ }^{2}$} & \multirow{2}{*}{\multicolumn{3}{|c|}{$\begin{array}{l}\text { Adequate/valid blood samples } \\
(\mathrm{N}=3038 / 66 \%)^{1}\end{array}$}} & \multirow{2}{*}{\multicolumn{3}{|c|}{$\begin{array}{l}\text { Inadequate blood samples or did not return } \\
\text { blood samples } \\
(\mathrm{N}=1559 / 34 \%)\end{array}$}} \\
\hline & & & & & & & & \\
\hline & & & $\mathrm{N}$ & $\%$ & Mean (SD) ${ }^{2}$ & $\mathrm{~N}$ & $\%$ & Mean (SD) ${ }^{2}$ \\
\hline Age (years) & 4573 & $57(4.7)$ & 3014 & & $57(4.1)$ & 1559 & & $57(5.1)$ \\
\hline $50-54$ & 1499 & & 953 & 32 & & 546 & 35 & \\
\hline $55-59$ & 1528 & & 1012 & 34 & & 516 & 33 & \\
\hline $60-64$ & 1409 & & 963 & 32 & & 446 & 29 & \\
\hline $65-69$ & 137 & & 86 & 3 & & 51 & 3 & \\
\hline Chi-square $p$-value ${ }^{5}$ & 0.045 & & & & & & & \\
\hline Body mass index $\left(\mathrm{kg} / \mathrm{m}^{2}\right)^{4}$ & 4243 & $25(4.6)$ & 2714 & & $25(4.4)$ & 1529 & & $25(4.9)$ \\
\hline$<25$ & 1562 & & 1244 & 46 & & 318 & 21 & \\
\hline$>25<29$ & 1680 & & 1082 & 40 & & 598 & 39 & \\
\hline$>29$ & 1001 & & 388 & 14 & & 613 & 40 & \\
\hline Chi-square $p$-value ${ }^{5}$ & $<0.001$ & & & & & & & \\
\hline Education (in years) & 4542 & & 3013 & & & 1529 & & \\
\hline$<=10$ & 830 & & 512 & 17 & & 318 & 21 & \\
\hline $11-14$ & 1830 & & 1232 & 41 & & 598 & 39 & \\
\hline $15+$ & 1882 & & 1269 & 42 & & 613 & 40 & \\
\hline Chi-square $p$-value ${ }^{5}$ & 0.007 & & & & & & & \\
\hline Physical activity (less strenuous) ${ }^{3}$ & 3661 & & 2414 & & & 1247 & & \\
\hline \multicolumn{9}{|l|}{ Hours per week } \\
\hline 0 & 86 & & 47 & 2 & & 39 & 3 & \\
\hline 1 & 422 & & 275 & 11 & & 147 & 12 & \\
\hline 2 to 3 & 1620 & & 1082 & 45 & & 538 & 43 & \\
\hline 4 to 5 & 917 & & 605 & 25 & & 312 & 25 & \\
\hline $6+$ & 616 & & 405 & 17 & & 211 & 17 & \\
\hline Chi-square $p$-value ${ }^{5}$ & 0.24 & & & & & & & \\
\hline Physical activity (strenuous) & 3557 & & 2353 & & & 1204 & & \\
\hline \multicolumn{9}{|l|}{ Hours per week } \\
\hline 0 & 1521 & & 986 & 42 & & 535 & 44 & \\
\hline 1 & 859 & & 571 & 24 & & 288 & 24 & \\
\hline 2 to 3 & 929 & & 638 & 27 & & 291 & 24 & \\
\hline 4 to 5 & 180 & & 116 & 5 & & 64 & 5 & \\
\hline $6+$ & 68 & & 42 & 2 & & 26 & 2 & \\
\hline Chi-square $p$-value ${ }^{5}$ & 0.32 & & & & & & & \\
\hline Smoking & 3649 & & 2397 & & & 1252 & & \\
\hline Never & 1583 & & 1096 & 46 & & 487 & 39 & \\
\hline Current & 778 & & 431 & 18 & & 347 & 28 & \\
\hline Past & 1288 & & 870 & 36 & & 418 & 33 & \\
\hline Chi-square $p$-value ${ }^{5}$ & $<0.001$ & & & & & & & \\
\hline
\end{tabular}

${ }^{1}$ Adequate/valid samples were samples returned in an aluminium bag with a desiccant pouch while invalid samples were samples without a dessicant pouch or aluminium bag.

${ }^{2}$ Unadjusted mean and standard deviation.

${ }^{3}$ Physical activity: less strenuous = walking, bicycling, working in the garden more strenuous = aerobic, running, bicycling at high intensity.

${ }^{4}$ excluded women with height $<125$, and weight $<30 \mathrm{~kg}>170 \mathrm{~kg}$.

${ }^{5}$ Compared the adequate $(n=3038)$ with the inadequate blood samples $(n=1559)$. 
in each spot. Samples were considered valid if and only if they were shipped in aluminum bags with the desiccant pouch. The amount of blood received was assessed by the number and size of the blood spots. Samples were classified into three categories: (a) filled, (b) small and (c) empty blood spots (a spot is the area within the circle, $13 \mathrm{~mm}$ in diameter that is supposed to be filled with blood). In a "filled blood spot" the spot was completely or almost completely filled with blood. Such a spot contained approximately $50 \mu \mathrm{l}$ of blood and was enough for about 7 punches. A punch is $3.2 \mathrm{~mm}$ in diameter and would provide $3.1 \mu \mathrm{l}$ of blood [19]. A "small blood spot" was defined as a blood spot sufficient for only one punch. An "empty blood spot" was defined as a blood spot with less blood than $3.2 \mathrm{~mm}$ in diameter or completely empty. The DBS cards with blood were stored in the laboratory at $-80^{\circ} \mathrm{C}$.

\section{Analysis of blood samples}

A subset of 381 valid samples was selected for analysis of vitamin $\mathrm{D}$ and carotenoids (lutein, zeaxanthin, $\beta$ kryptoxanthin, $\alpha$-carotene, $\beta$-carotene and lycopene). The 381 samples were selected based on the following inclusion criteria: age at screening $>50$ years, energy intake $>2100 \mathrm{~kJ}$ and $<15000 \mathrm{~kJ}$ and body mass index $>$ $15 \mathrm{~kg} / \mathrm{m}^{2}$ and $<50 \mathrm{~kg} / \mathrm{m}^{2}$.

High-performance liquid chromatography with ultraviolet detection and liquid chromatography-mass spectrometry were used for analysis of carotenoids and vitamin $\mathrm{D}$, respectively $[20,21]$.

Hematocrit values in normal adult women are about $50 \%$. In order to compare DBS results with results from analysis of plasma, all DBS values were multiplied with a factor of $2[2]$.

\section{Statistics}

We used excel to calculate unadjusted chisquare tests for the overall differences in proportions (test for homogeneity). All tests of significance were 2-sided and $\mathrm{p}<0.05$ was considered statistically significant. The IBM Statistical Package for Social Sciences (SPSS) was used for calculating frequencies in Table 2 [Version 20 (IBM Corp 2012) Armonk, NY:IBM Corp].

\section{Ethics statement}

The present study was conducted according to the Declaration of Helsinki guidelines and approved by The Regional Committee for Medical Research Ethics. All the participants gave their written informed consent.

\section{Results}

Of the 4,597 sampling kits sent to participants, we received DBS samples from 3,263 women (71.0\%) (Figure 2) and saliva samples from 3,258 women (70.9\%). A total of $117(2.5 \%)$ of the 4,597 mailed kits were returned due to
Table 2 Number of participants submitting adequately filled spots and blood spots allowing at least one punch for analysis

\begin{tabular}{lll}
\hline $\begin{array}{l}\text { Number of } \\
\text { blood } \\
\text { spots }\end{array}$ & $\begin{array}{l}\text { Number of participants } \\
\text { with adequately filled } \\
\text { blood spots }\end{array}$ & $\begin{array}{l}\text { Number of participants } \\
\text { with blood spots allowing } \\
\text { at least one punch }{ }^{1}\end{array}$ \\
\hline 10 & 2,418 & 2,655 \\
$\geq 9$ & 2,521 & 2,729 \\
$\geq 8$ & 2,613 & 2,796 \\
$\geq 7$ & 2,692 & 2,850 \\
$\geq 6$ & 2,750 & 2,896 \\
$\geq 5$ & 2,834 & 2,964 \\
$\geq 4$ & 2,871 & 2,988 \\
$\geq 3$ & 2,906 & 3,011 \\
$\geq 2$ & 2,938 & 3,026 \\
$\geq 1$ & 2,960 & 3,032 \\
\hline
\end{tabular}

'a punch is $3.2 \mathrm{~mm}$ in diameter and would provide $3.1 \mu \mathrm{l}$ of blood.

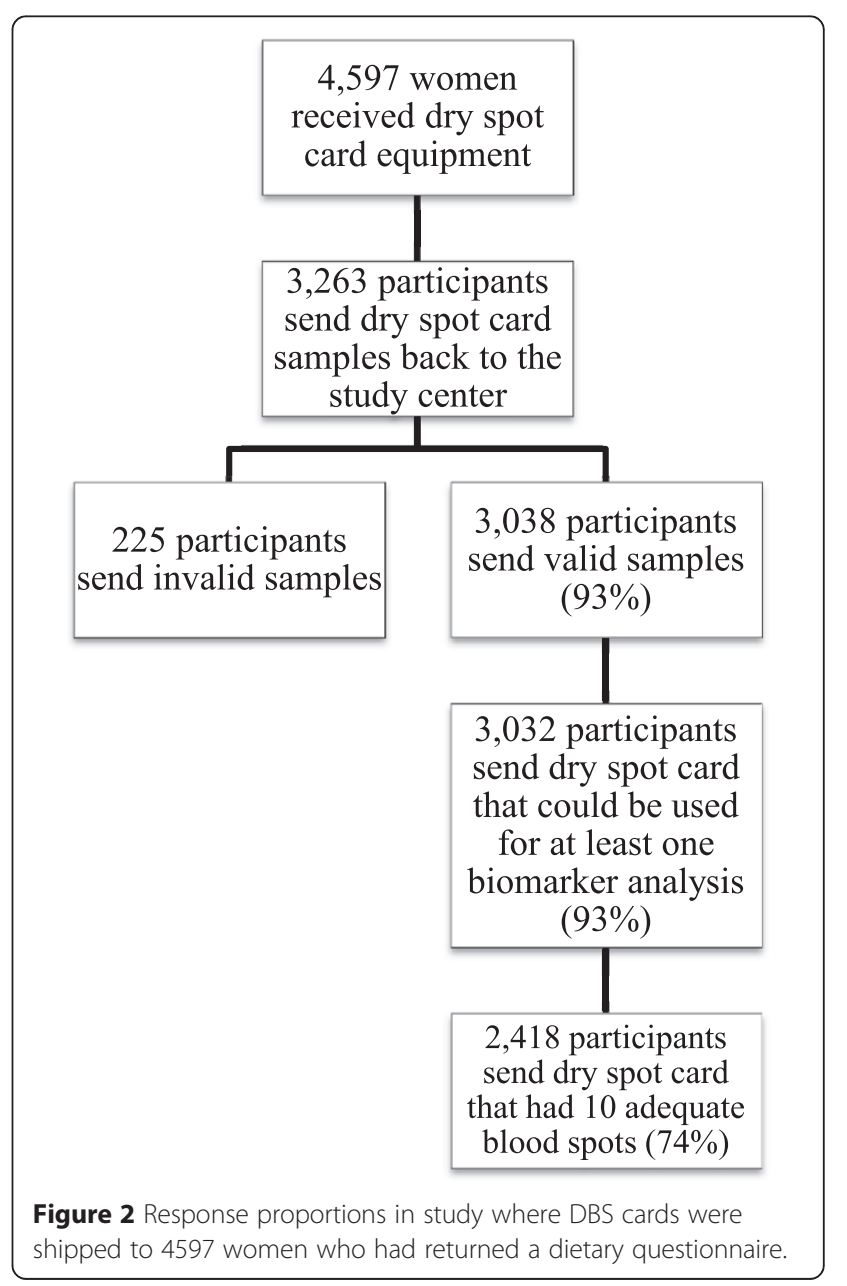


erroneous addresses and 12 were lost during the mailing process.

We received $312(6.8 \%)$ phone calls from the 4,597 participants. Reasons for the phone calls included the following: participants that refused $(n=90)$ or were unavailable to participate of other reasons $(n=13)$, participants needing a second DBS card $(n=84)$ or other equipment $(n=25)$, sickness and medications $(n=31)$, participants not able to get blood after finger-prick $(\mathrm{n}=9)$ and additional questions or reasons $(n=60)$ (Figure 3 ).

Of the 3,263 women who submitted the DBS samples, a total of 300 participants $(9.2 \%)$ wrote comments on the form included with the sampling kit (Figure 4). Most of these comments were regarding lack of blood $(n=189)$ and difficulty in performing the finger-prick test $(n=42)$. Some comments were also about broken lancets $(n=30)$, insufficient number of lancets $(n=30)$. Only a small number reported feeling unwell when performing the finger-prick test $(n=9)$.

Out of 3,263 received DBS samples, 3038 (93.1\%) were packed and shipped as instructed, while 225 participants (Figure 2) either omitted the desiccant pouches or failed to place the DBS cards in the aluminum bags as instructed. Because this could affect the stability of the biomarkers, we classified these as inadequate or invalid blood samples. There were a number of differences between the 3038 women with adequate samples and the 1559 women who did not return a sample or who returned an inadequate sample (Table 1). Those with valid samples tended to be slimmer, more highly educated and less likely to be current smokers.

Additionally, a few participants $(n=6)$ submitted DBS cards that only contained empty spots or spots with less

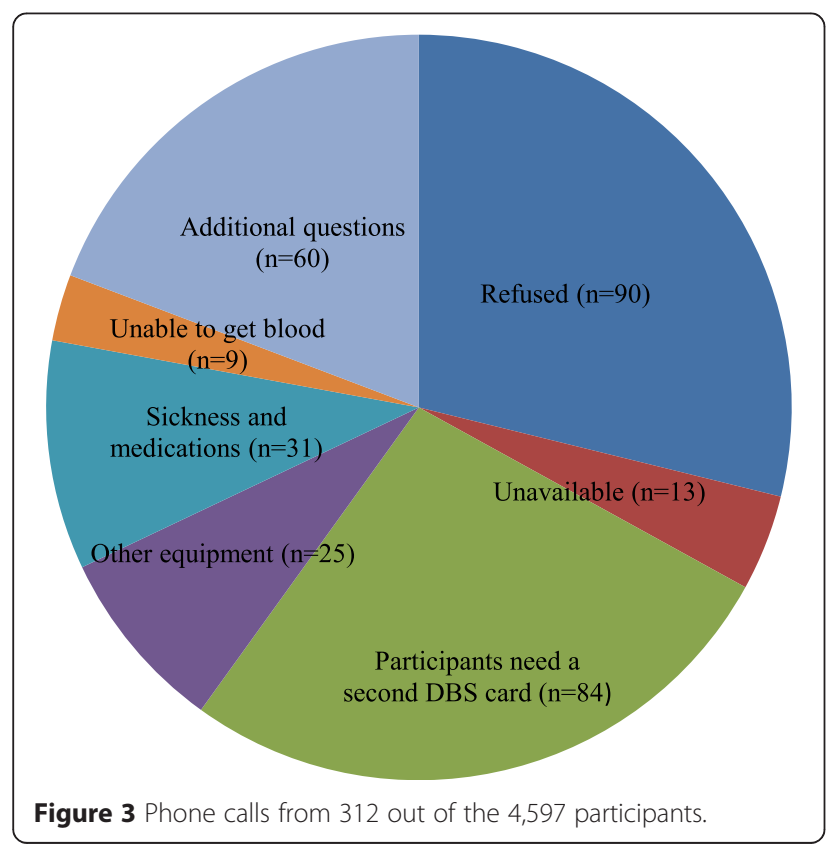

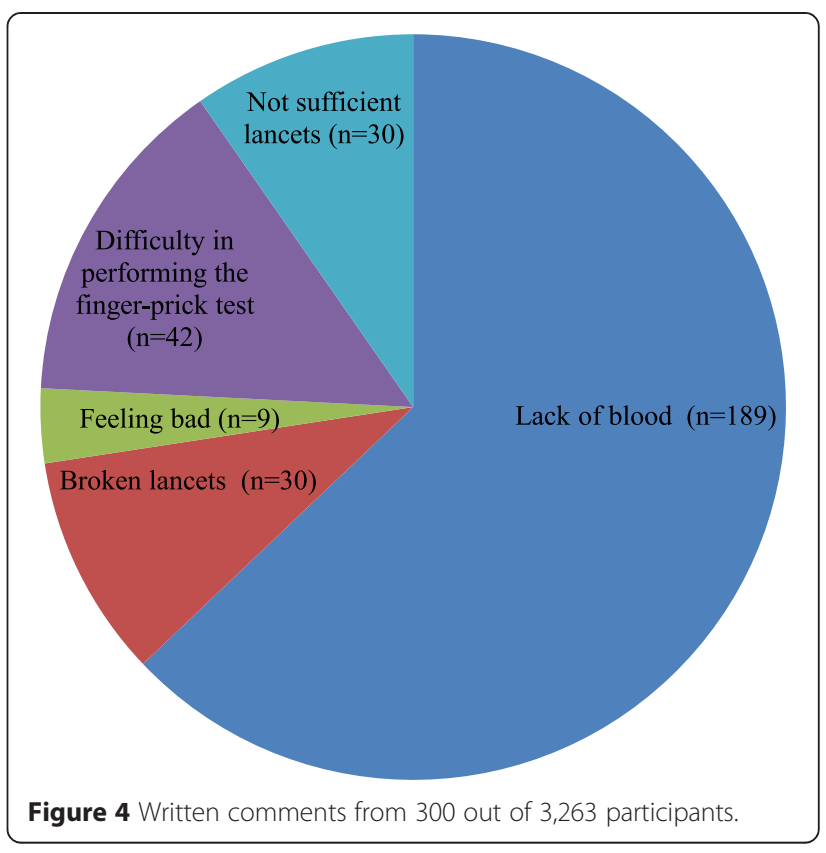

blood than required for a single punch. Out of 3,263 DBS cards submitted to the laboratory, 3,032 (92.9\%) could be used for at least one biomarker analysis (Table 2). Table 2 also presents the number of participants that were able to submit DBS cards with 1-10 adequately filled blood spots (with each spot enabling up to 7 punches for individual analysis) and 1-10 blood spots which allow at least one punch for analysis. Thus, 2,418 (74.1\%) DBS cards were returned with all 10 spots filled with blood according to the instructions. These DBS cards will allow up to 70 punches for separate analyses from each participant.

Measurements of carotenoids and vitamin D in a subset of 381 samples are shown in Table 3, where we also list results obtained in previous studies from Norway or Nordic countries [20,22-25]. The results demonstrate that plasma values are similar to those obtained in previous studies. One exception was lycopene, which was somewhat lower in this study than in the other studies, but higher than in the study from Finland.

\section{Discussion}

In the present study, we found that by sending out DBS and saliva sample collection kits with instructions to women aged 50-69 who had agreed to participate in a dietary study, self-collected samples were received from about $70 \%$ of the participants. The collection resulted in phone calls from about $7 \%$ of women, where about a third was related to the lancets, or difficulties in using them. Of the blood samples received, about 93\% were considered valid and could be used for at least one biomarker analysis. Overall $74 \%$ had 10 filled spots that would we used for up to 70 separate blood analyses. 
Table 3 The mean concentration of carotenoids and 25-hydroxy vitamin $D_{3}$ from DBS samples compared with plasma from other studies in theNordic countries

\begin{tabular}{|c|c|c|c|c|c|c|c|c|c|}
\hline & $\begin{array}{l}\text { Lutein } \\
(\mu \mathrm{mol} / \mathrm{L})\end{array}$ & $\begin{array}{l}\text { Zeaxanthin } \\
(\mu \mathrm{mol} / \mathrm{L})\end{array}$ & $\begin{array}{l}\beta \text {-kryptoxanthin } \\
(\mu \mathrm{mol} / \mathrm{L})\end{array}$ & $\begin{array}{l}\text { a-carotene } \\
(\mu \mathrm{mol} / \mathrm{L})\end{array}$ & $\begin{array}{l}\beta \text {-carotene } \\
(\mu \mathrm{mol} / \mathrm{L})\end{array}$ & $\begin{array}{l}\text { Lycopene } \\
(\mu \mathrm{mol} / \mathrm{L})\end{array}$ & $\begin{array}{l}\text { 25-hydroxy D3 } \\
\text { (nmol/L) }\end{array}$ & $\begin{array}{l}N(\text { Carotenoids - } \\
\text { vitamin } D=\end{array}$ & $\begin{array}{l}\text { References } \\
\text { (Carotenoids - } \\
\text { vitamin D) }\end{array}$ \\
\hline $\begin{array}{l}\text { Norway - DBS samples } \\
\text { present study mean (SD) }{ }^{1}\end{array}$ & $0.23( \pm 0.13)$ & $0.046( \pm 0.02)$ & $0.16( \pm 0.11)$ & $0.13( \pm 0.10)$ & $0.43( \pm 0.29)$ & $0.25( \pm 0.12)$ & $43( \pm 12)$ & $403-403$ & $\begin{array}{l}\text { The present } \\
\text { study }\end{array}$ \\
\hline $\begin{array}{l}\text { Norway previous study } \\
\text { mean (SD) }\end{array}$ & $0.17( \pm 0.07)$ & $0.04( \pm 0.02)$ & $0.16( \pm 0.11)$ & $0.14( \pm 0.12)$ & $0.50( \pm 0.32)$ & $0.63( \pm 0.33)$ & n.a & 346 - n.a. & {$[20]$} \\
\hline Denmark study mean (SD) & $0.34( \pm 0.14)$ & $0.07( \pm 0.04)$ & $0.23( \pm 0.21)$ & $0.22( \pm 0.18)$ & $0.47( \pm 0.38)$ & $0.53( \pm 0.29)$ & $75( \pm 29)$ & $98-2,016$ & {$[22,23]$} \\
\hline Sweden study mean (SD) & $0.28( \pm 0.12)$ & $0.06( \pm 0.04)$ & $0.20( \pm 0.19)$ & $0.20( \pm 0.22)$ & $0.54( \pm 0.73)$ & $0.52( \pm 0.27)$ & $69( \pm 23)$ & $97-116$ & {$[22,23]$} \\
\hline Finland study mean (SD) & $0.20( \pm 0.10)$ & $0.04( \pm 0,02)$ & $0.20( \pm 0.18)$ & $0.19( \pm 0.13)$ & $0.69( \pm 0.47)$ & $0.09( \pm 0.06)$ & $38.1( \pm 4.6)$ & $620-1,283$ & {$[25,28]$} \\
\hline
\end{tabular}

Values are means and SD (standard derivation).

n.a. $=$ not analyzed.

n.a. $=$ not analyzed.
1 order to compare DBS results with results from analysis of plasma, all DBS values were multiplied with a factor of 2 . 
Measurement of two selected biomarkers showed similar results to those obtained in other studies.

The participation rate in this study of self-sampling was good. The fact that response proportion was similar for the DBS samples and saliva samples, suggests that those who are willing to provide a biological sample are also willing to do so, even if it entails a finger prick. However, women who provided DBS and saliva samples had agreed to participate in the study and had also completed a dietary questionnaire. One could argue that the relatively high proportion that responded represented a highly motivated group. Further, women with an adequate/valid sample were more highly educated and healthier than those who did not participate or had an invalid sample. The largest difference was found for smoking, confirming the participants represented a selected group. A case-control study from the US that included a \$2.00 bill to encourage participation, yielded similar participation (68\%), and found that the participation with DBS was better than venipuncture (62\%) [8]. Their study was, however smaller, with 134 female cancer cases and 256 controls. In the present study we did not include a cash incentive, but still obtained a participation rate of $70 \%$ among those who had already returned a dietary questionnaire.

We also determined the usefulness or quality of DBS cards returned to the laboratory. Based on our assessments, about $93 \%$ of the received DBS cards had sufficient blood spots for at least one biomarker analysis and most of these had 10 adequate spots.

Only about $7 \%$ of the participants contacted the study center by phone. Although a third of these were refusals, about a third were regarding lack of or malfunctioning equipment (lancets). The study staff tested out a series of lancets in advance, both internally and in a pilot, before deciding on the one that was the most reliable. Since several participants still complained about the lancet, any future study should test in more detail several lancets before commencing a large epidemiological study, or consider including two lancets.

The levels of the biomarkers (vitamin D and carotenoids) analyzed in this study were compared with findings from other studies to confirm the reliability of DBS to plasma analysis of biomarkers. The concentrations of these biomarkers in human blood vary across Europe $[22,23]$. We compared our results with those in similar population samples (women, comparable age) from studies in Nordic countries [23-28]. Levels of all biomarkers analyzed in the present study, were similar with those from other studies. The levels of lycopene in the present study were somewhat lower than three other studies but higher than a study from Finland. These variations probably reflect different dietary intake of tomato products like tomato sauce, pizza and ketchup [29] in the different populations, since these foods are the major sources for lycopene.

Some caution must be taken when comparing DBS data with plasma analyses performed in blood samples taken by venipuncture. Absolute values from DBS samples (i.e. whole blood) are expected to be about $50 \%$ of values reported in plasma [2], because whole blood includes blood cells as well as plasma. In normal adult women, hematocrit values are about $50 \%$, and thus about half of the blood volume represents blood cells. Thus, in the comparison between DBS and plasma analysis, all DBS values were multiplied with a factor of 2 . In addition, the recovery or extraction of biomarkers from DBS might also differ in comparison to plasma. Thus, development of separate reference ranges of different biomarkers in DBS cards is needed.

Unlike venipuncture, trained personnel were not required for DBS collection and the transportation and storage of samples was easier. The reduced storage space requirements are also a major advantage, especially when thousands of samples are to be collected in large epidemiological studies. The volume needed for storage of DBS samples is typically less than one tenth of similar aliquots of plasma samples. Furthermore, obtaining small samples for analysis is often also much simpler from DBS cards, since no thawing and refreezing of plasma samples are needed.

A major advantage of the DBS cards is reduced cost, a typical limiting factor when performing epidemiological studies. A direct comparison between the cost when using self-sampled DBS cards and plasma samples from venipuncture by health personnel is difficult, but will in most instances be very large (e.g. reduced costs for transportation of participants to study or blood collection center, for equipment, storage and personnel).

There are a number of advantages of sample collection by postal service. It may increase participation rate in a population-based study requiring blood samples. In particular, this sample collection technique increases the possibility of obtaining samples from people living in remote rural areas. Further, the rapidness of the data collection, collecting samples from over 3000 women in less than 3 months, is a strong advantage. There are also some limitations with self-sampled DBS collection via the postal service. One of the disadvantages is that the participants must follow the instructions carefully and failure to do so may affect the results. In our study, we observed that $7 \%$ did not return the samples packaged as we had instructed with the desiccant and inside the aluminum bag.

\section{Conclusion}

We explored the feasibility of self-sampled DBS cards and saliva samples shipped by postal service. Response 
proportions were $70.9 \%$ and $71.0 \%$, respectively. Of the DBS samples obtained, over $90 \%$ were considered valid and sufficient for at least one biomarker analysis. The data collection resulted in a limited number of phone calls to the study center. Our study suggests that the DBS collection method is efficient, yields a high response proportion and blood spots that can be used in large population-based studies. Overall self-sampled DBS and saliva samples shipped through the postal service appears to offer a low cost, effective and feasible means for collecting biological samples in epidemiological studies.

\section{Additional file}

Additional file 1: Dried blood sample (DBS) collection instructions.

\section{Abbreviations}

DBS: Dried blood spot; DNA: Deoxyribonucleic acid.

\section{Competing interests}

RB and TEG have an interest in the company Vitas AS. Vitas was established by the Oslo Innovation Center. The authors declare that they have no competing interests.

\section{Authors' contributions}

AKS was responsible for sample collection, data acquisition, drafting and revising of the manuscript. NEB did the biomarker analysis in patient samples, sample collection and revising of the manuscript. ME did statistical analysis, sample collection and revising of the manuscript. TEG was responsible for the blood sample collection instructions and revising of the manuscript. GU and RB planned the study and revised the manuscript. All authors read and approved the final manuscript.

\section{Acknowledgements}

This work was supported by grants from The Norwegian Cancer Society, The Norwegian Research Council and The Throne Holst Foundation.

\section{Author details}

${ }^{1}$ Norwegian Institute of Public Health, 0456 Oslo, Norway. ${ }^{2}$ Department of Nutrition, Institute of Basic Medical Sciences, University of Oslo, 0316 Oslo, Norway. ${ }^{3}$ Vitas AS, Oslo Innovation Park, N-0349 Oslo, Norway. ${ }^{4}$ Department of Clinical Service, Division of Cancer Medicine, Surgery and Transplantation, Oslo University Hospital, 0424 Oslo, Norway. ${ }^{5}$ Cancer Registry of Norway, P.O. Box 5313, 0304 Oslo, Norway. ${ }^{6}$ Department of Preventive Medicine, University of Southern California, 90032-3628 Los Angeles, CA, USA.

Received: 6 October 2014 Accepted: 26 March 2015

Published online: 11 April 2015

\section{References}

1. Edelbroek PM, van der Heijden J, Stolk LM. Dried blood spot methods in therapeutic drug monitoring: methods, assays, and pitfalls. Ther Drug Monit. 2009;31(3):327-36.

2. McDade TW, Williams S, Snodgrass JJ. What a drop can do: Dried blood spots as a minimally invasive method for integrating biomarkers into population-based research. Demography. 2007;44(4):899-925.

3. Pomelova VG, Osin NS. Prospects of the integration of dry blood spot technology with human health and environmental population studies. Vestn Ross Akad Med Nauk. 2007;12:10-6.

4. Chambers AG, Percy AJ, Hardie DB, Borchers $\mathrm{CH}$. Comparison of proteins in whole blood and dried blood spot samples by LC/MS/MS. J Am Soc Mass Spectrom. 2013;24(9):1338-45.

5. Deglon J, Versace F, Lauer E, Widmer C, Mangin P, Thomas A, et al. Rapid LC-MS/MS quantification of the major benzodiazepines and their metabolites on dried blood spots using a simple and cost-effective sample pretreatment. Bioanalysis. 2012;4(11):1337-50.

6. Leruez-Ville M, Ngin S, Guilleminot T, Kfutwah A, Moussa S, Tran T, et al. Detection of cytomegalovirus DNA on dried blood spots collected from infants infected with HIV: An in-house method adaptable in resource-limited settings. J Virol Methods. 2013;193(2):503-7.

7. Sewell AC, Haskins ME, Giger U. Dried blood spots for the enzymatic diagnosis of lysosomal storage diseases in dogs and cats. Vet Clin Pathol. 2012;41(4):548-57.

8. Bhatti P, Kampa D, Alexander BH, McClure C, Ringer D, Doody MM, et al. Blood spots as an alternative to whole blood collection and the effect of a small monetary incentive to increase participation in genetic association studies. BMC Med Res Methodol. 2009;9:76.

9. Fokkema MR, Bakker AJ, de Boer F, Kooistra J, de Vries S, Wolthuis A. HbA1C measurements from dried blood spots: validation and patient satisfaction. Clin Chem Lab Med. 2009;47(10):1259-64.

10. Williams SR, McDade TW. The use of dried blood spot sampling in the national social life, health, and aging project. J Gerontol B Psychol Sci Soc Sci. 2009;64:1131-6.

11. Al-Delaimy WK, Slimani N, Ferrari P, Key T, Spencer E, Johansson I, et al. Plasma carotenoids as biomarkers of intake of fruits and vegetables: ecological-level correlations in the European Prospective Investigation into Cancer and Nutrition (EPIC). Eur J Clin Nutr. 2005;59(12):1397-408.

12. PoolZobel BL, Bub A, Muller H, Wollowski I, Rechkemmer G. Consumption of vegetables reduces genetic damage in humans: first results of a human intervention trial with carotenoid-rich foods. Carcinogenesis. 1997;18(9):1847-50.

13. Woodside JV, Young IS, Gilchrist SECM, Vioque J, Chakravarthy U, De Jong PTVM, et al. Factors associated with serum/plasma concentrations of vitamins A, C, E and carotenoids in older people throughout Europe: the EUREYE study. Eur J Nutr. 2013;52(5):1493-501.

14. Jauregui MEC, Carrillo MDC, Romo FPG. Carotenoids and their antioxidant function: a review. Arch Latinoam Nutr. 2011;61(3):233-41.

15. Dupont E, Gomez J, Bilodeau D. Beyond UV radiation: a skin under challenge. Int J Cosmet Sci. 2013;35(3):224-32.

16. McCarty CA. Sunlight exposure assessment: can we accurately assess vitamin D exposure from sunlight questionnaires? Am J Clin Nutr. 2008;87(4):1097S-101.

17. Milliken SVI, Wassall H, Lewis BJ, Logie J, Barker RN, Macdonald H, et al. Effects of ultraviolet light on human serum 25-hydroxyvitamin D and systemic immune function. J Allergy Clin Immunol. 2012;129(6):1554-61.

18. Qureshi SA, Lund AC, Veierod MB, Carlsen MH, Blomhoff R, Andersen LF, et al. Food items contributing most to variation in antioxidant intake; a cross-sectional study among Norwegian women. BMC Public Health. 2014;14(1):45.

19. Bastani NE, Gundersen TE, Blomhoff R. Dried blood spot (DBS) sample collection for determination of the oxidative stress biomarker 8-epiPGF(2alpha) in humans using liquid chromatography/tandem mass spectrometry. Rapid Commun Mass Spectrom. 2012;26(6):645-52.

20. Bastani NE, Kostovski E, Sakhi AK, Karlsen A, Carlsen MH, Hjeltnes N, et al. Reduced antioxidant defense and increased oxidative stress in spinal cord injured patients. Arch Phys Med Rehabil. 2012;93(12):2223-8.

21. Holvik K, Ahmed LA, Forsmo S, Gjesdal CG, Grimnes G, Samuelsen SO, et al. Low serum levels of 25 -Hydroxyvitamin $D$ predict hip fracture in the elderly: a NOREPOS Study. J Clin Endocrinol Metab. 2013;98(8):3341-50.

22. Al-Delaimy WK, van Kappel AL, Ferrari P, Slimani N, Steghens JP, Bingham S, et al. Plasma levels of six carotenoids in nine European countries: report from the European Prospective Investigation into Cancer and Nutrition (EPIC). Public Health Nutr. 2004;7(6):713-22.

23. Grant WB, Juzeniene A, Moan JE. Health benefit of increased serum $25(\mathrm{OH}) \mathrm{D}$ levels from oral intake and ultraviolet-B irradiance in the Nordic countries. Scand J Public Health. 2011;39(1):70-8.

24. Karppi J, Kurl S, Makikallio TH, Ronkainen K, Laukkanen JA. Low levels of plasma carotenoids are associated with an increased risk of atrial fibrillation. Eur J Epidemiol. 2013;28(1):45-53.

25. Kilkkinen A, Knekt P, Heliovaara M, Rissanen H, Marniemi J, Hakulinen T, et al. Vitamin D status and the risk of lung cancer: a cohort study in Finland. Cancer Epidemiol Biomarkers Prev. 2008;17(11):3274-8.

26. Burgaz A, Akesson A, Oster A, Michaelsson K, Wolk A. Associations of diet, supplement use, and ultraviolet B radiation exposure with vitamin D status in Swedish women during winter. Am J Clin Nutr. 2007;86(5):1399-404. 
27. Moller UK, Streym S, Heickendorff L, Mosekilde L, Rejnmark L. Effects of $25 \mathrm{OHD}$ concentrations on chances of pregnancy and pregnancy outcomes: a cohort study in healthy Danish women. Eur J Clin Nutr. 2012;66(7):862-8.

28. Rejnmark L, Buus NH, Vestergaard P, Andreasen F, Heickendorff L, Larsen $\mathrm{ML}$, et al. Effects of simvastatin treatment in postmenopausal osteopenic women: A randomized controlled trial. J Bone Miner Res. 2003;18:S32-S32.

29. Hendrickson SJ, Willett WC, Rosner BA, Eliassen AH. Food predictors of plasma carotenoids. Nutrients. 2013:5(10):4051-66.

\section{Submit your next manuscript to BioMed Central} and take full advantage of:

- Convenient online submission

- Thorough peer review

- No space constraints or color figure charges

- Immediate publication on acceptance

- Inclusion in PubMed, CAS, Scopus and Google Scholar

- Research which is freely available for redistribution 